\title{
Modeling the Transition State Structures of the Reductive-Half Reaction Active Site of Xanthine Oxidase Bound to Guanine Analogues: A Density Functional Theory Approach
}

\author{
Mamaru Bitew Alem ${ }^{1}$, Yilkal Bezie Ayele ${ }^{2}$ \\ ${ }^{1}$ Department of Chemistry, Debre Markos University, Ethiopia \\ ${ }^{2}$ Department of Biotechnology, Debre Markos University, Ethiopia \\ Correspondence: Mamaru Bitew Alem, Department of Chemistry, Debre Markos University, Ethiopia. \\ E-mail: mamaru2005@gmail.com
}

Received: November 28, 2017 Accepted: January 16, 2018 Online Published: January 28, 2018

doi:10.5539/ijc.v10n1p137

URL: https://doi.org/10.5539/ijc.v10n1p137

\begin{abstract}
Modeling and characterization the transition state structure of enzyme catalyzed reactions is essential. A DFT method employing B3LYP level of theory with 6-31G (d',p') basis set for non-metals and LanL2DZ basis set for molybdenum have been used. The bond orders of chemical fragments were calculated using AOmix softaware. The effect of chalcogen replacement, amine group and methyl group in the parent structure of xanthine bound to xanthine oxidase active site were compared. The transition state structure of model substrates (2AX, 2A6TP, 2A6SP and 2A6MP) bound to the truncated form of XO active site has been confirmed by the presence of one negative imaginary frequencies $\left(\mathrm{s}^{-1}\right)(-60),(-140),(-230)$ and (-270), respectively. The corresponding normalized energy barriers $(\mathrm{kcal} / \mathrm{mol})$ from pre-transition state to the transition state, respectively, are (13.869), (21.753), (23.109) and (0.212). In this work, 2A6SP and 2A6TP substrates were found to be potential xanthine oxidase inhibitors. The large bond distances and minimum bond order for $\mathrm{C}_{\mathrm{RH}}-\mathrm{H}_{\mathrm{RH}}$ bond, and small bond distances and maximum bond order for $\mathrm{S}_{\mathrm{Mo}}-\mathrm{H}_{\mathrm{RH}}$ bond at the transition state for chalcogen replaced 2AX confirms early transition state structure. Methyl substituted 2AX analog found to have post transition state structure. A potential xanthine oxidase inhibitor can be designed from purine family enzymes using DFT approach.
\end{abstract}

Keywords/Phrases: DFT, xanthine oxidase, modeling, stepwise mechanism, transition state

\section{Introduction}

Xanthine oxidoreductase (XOR) is a molybdenum-containing enzyme encoded by the human genome and catalyzes the sequential hydroxylation of hypoxanthine to xanthine and xanthine to uric acid [Enroth et al. (2000), Okamoto et al. (2004) and Nishino, Okamoto, Eger and Pai (2008)]. The enzyme was first discovered, in 1902 from bovine milk by F. Schardinger [Berry and Hare (2004), and Enroth et al. (2000)] as aldehyde reductase. But, Dixon et al. (1926) isolated the enzyme from cow's milk and showed that the enzyme was identical to the xanthine-oxidizing enzyme [Nishino et al. (2008)]. Since then, the enzyme has been routinely isolated from various sources [Enroth et al. (2000) and Okamoto et al. (2004)]. The X-ray crystal structure for XO (xanthine oxidase) enzymes has been resolved from various sources such as bovine milk xanthine oxidase (bmXOR) [Enroth et al., (2000)] (Figure 1.1). 


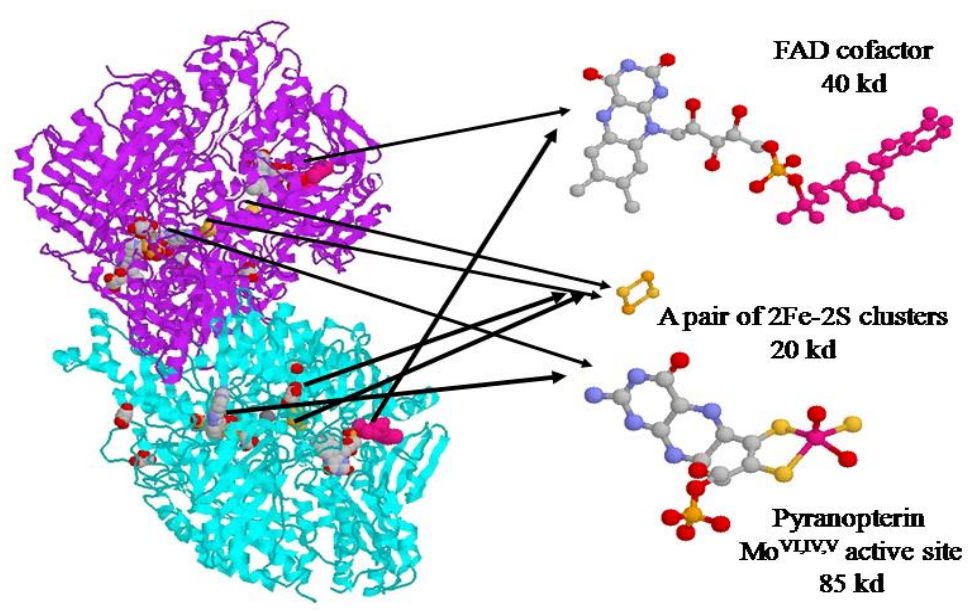

Figure 1.1. The crystal structure of bovine milk xanthine oxidase (left) and arrangement of the redox active centers: Mo MPT, [2Fe-2S] cluster and FAD (PDB accession code of 1V97) [Okamoto et al. (2004)]

The illustration was prepared using protein explorer [Martz (2002)]

The $b m X O R$ enzyme is a homodimer with a molecular mass of about $\sim 300 \mathrm{kDa}$ [Enroth et al. (2000) and Okamoto et al. (2004)]. Each monomer consists of four redox active centers: Molybdopterin cofactor, a pair of non-identical 2Fe-2S centers, and one FAD (Flavin adenine dinucleotide) cofactor [Cao, Pauff, and Hille, (2011), Leimkühler, Stockert, Igarashi, Nishino, and Hille, (2004) and Pauff, Cao and Hille, (2008)]. The smallest (S) subunits (20-kDa each, consisting two pairs of $\left[\mathrm{Fe}_{2} \mathrm{~S}_{2}\right]\left(\mathrm{S}_{\mathrm{Cys}}\right)_{4}$ clusters) are connected by a long segment to the medium (M) subunits (40-kDa each, consisting two FAD cofactors). Similarly, the medium subunits are connected to the large (L) subunits (85-kDa each, consisting two molybdopterin cofactors) [Mohamed, Al-Omar, El-Subbagh, Beedham, and Smith, (2005) and Schwarz and Mendel, (2006)]. The enzyme, XOR has two interconvertible forms, Xanthine Dehydrogenase (XDH) and XO [and Berry and Hare, (2004) and Enroth et al. (2000)]. The enzyme, bmXOR from mammalian sources including human, is synthesized as the dehydrogenase form, but it can be readily converted to the oxidase (XO) form upon oxidation of sulfhydryl residue [Leimkühler et al. (2004), Pauff, Zhang, Bell, and Hille, (2008) and Pauff, Cao, and Hille, (2009)]. The main differences in the catalytic properties of XDH and $\mathrm{XO}$ are the reactivity of the FAD cofactor towards the competing electron acceptors, $\mathrm{NAD}^{+}$and molecular oxygen, which are electron acceptors for $\mathrm{XDH}$ and $\mathrm{XO}$, respectively [Pauff, Zhang, Bell, and Hille, (2007), Pauff et al., (2008) and Pauff et al. (2009)].

The enzyme is widely distributed throughout various mammalian organs and microorganism cells. In mammals, including human, the enzyme is known to be found in various organs of our body including kidney, liver, small intestine, and lactating mammary gland [Pauff et al., (2007)]. In addition to its role in hydroxylation of various N-hetrocyclic compounds, it is suggested to be involved in drug oxidation, activation, and detoxification of xenobiotics [Mohamed et al., (2005)]. However, the most noticeable disease in humans is the deposition of uric acid, known to be responsible for gouty conditions [Romao, (2009)]. This condition is more pronounced in the joints, through the deposition crystals of sodium urate [Kalra, Jena, Tikoo, and Mukhopadhyay, (2007)]. The hydroxylation products are the main reason for gouty condition or hyperuricemia which is a painful disease occurred in joints [Bjelakovic et al., (2002), Kalra et al., (2007) and Romao, (2009)]. In the course of the reaction, reactive oxygen species (ROS), $\mathrm{O}_{2}{ }^{-}$and $\mathrm{H}_{2} \mathrm{O}_{2}$ are generated at FAD as end product of the reaction [Berry and Hare, (2004)]. These reactive oxygen species together with the hydroxylated product of the reaction, uric acid, are suggested in different pathological states, in the area of human health. It is also involved in different pathological states such as endothelia dysfunction, hypertension, carcinogenesis, hepatitis, oxidative damage, and heart failure [Berry and Hare, (2004)]. Hence, health organizations show interest in the enzyme as the enzyme is more frequently linked to major metabolic pathways of drugs and due to its adverse effect in the area of human health [Mohamed et al., (2005), and Alfaro and Jones, (2008)]. Thus, understanding the catalytic cycle of the reaction mechanism would be beneficial from human health perspective [Leimkühler et al., (2004), Pauff et al. (2007), Pauff et al. (2008), Zhang, and Wu, (2005)].

As shown in Figure 1.1, the redox sites of the $b m X O R$ enzymes are organized in a linear fashion, ideal for electron transfer. As with many oxidoreductase enzymes, the redox sites are characterized for their suitability to undergo simultaneous interaction with both the reducing and oxidizing substrates. The reducing substrates react at the reductive and the oxidizing substrates at the oxidative half-reaction active sites [Voityuk, Albert, Romao, Huber, and Roesch, (1998)]. They also need additional components (such as pairs of $\left[\mathrm{Fe}_{2} \mathrm{~S}_{2}\right]\left(\mathrm{S}_{\mathrm{Cys}}\right)_{4}$ clusters) to facilitate the flow of electrons between the 
reduction and oxidation half-reaction sites [Pauff et al. (2009), and Xia, Dempski, and Hille, (1999)]. The reaction stoichiometries of these enzymes are unique among other hydroxylation reactions catalyzed by mono-oxygenase enzymes. Monoxygenase enzymes hydroxylate their substrates using the oxygen, derived from molecular oxygen (equation 1). Unlike the mono-oxygenase enzymes, the XOR enzymes use oxygen derived from water and generates a pair of reducing equivalents (equation 2) [Choi, Stockert, Leimkuhler, Hille, (2004), Hille, Kim, and Hemann, (1993) and Hille, (2006)].

$$
\begin{aligned}
& \mathrm{RH}+2 e^{-}+2 \mathrm{H}^{+} \stackrel{\text { Heme }}{\longrightarrow} \mathrm{ROH}+\mathrm{H}_{2} \mathrm{O} \ldots . \\
& \mathrm{RH}+\mathrm{H}_{2} \mathrm{O} \stackrel{\text { MoVI }}{\longrightarrow} \mathrm{ROH}+2 \mathrm{H}^{+}+2 e^{-} .
\end{aligned}
$$

\subsection{Overview of the Catalysis Stage and the Nature of the Transition State}

The catalysis stage of the reaction mechanism is the main concern of theoretical research since the transition state structure is part of this stage. The geometry of the transition state structure is central in understanding the catalytic reaction mechanism [Ayala and Schlegel, (1997)] although the smallest fraction of the catalytic cycle is spent in the transition state [Schramm, (1998)]. As shown by the mechanistic transformation (Scheme 1.2), the transformation of the tetrahedral Michaelis-Menten complex $\left[(\right.$ Enzyme $)-\left(\mathrm{MoVI}=\mathrm{O}(=\mathrm{S})\left(-\mathrm{O}-\mathrm{C}_{\mathrm{RH}}\right)\right]$ to the product bound intermediate $\left[\left(\right.\right.$ Enzyme)-(MoIV=O(-SH) $\left.\left(-\mathrm{O}-\mathrm{C}_{\mathrm{R}}\right)\right]$ is proposed to pass through the tetrahedral transition state (Schemes 1.1, Structure b). The generalized reaction equation for reactions to form their product is shown in Scheme 1.2. The tetrahedral transition state complex ((Enzyme)-[MoVI=S--- $\left.\left.\mathrm{H}_{\mathrm{RH}}{ }^{--} \mathrm{C}_{\mathrm{RH}}\right] \#\right)$, shown in Scheme 1.2, is described by placing the substrate bound hydrogen $\left(\mathrm{H}_{\mathrm{RH}}\right)$ between the Mo bound sulfido $\left(\mathrm{S}_{\mathrm{Mo}}\right)$ terminal and the substrate $\left(\mathrm{C}_{\mathrm{RH}}\right)$ bound carbon. Depending on the

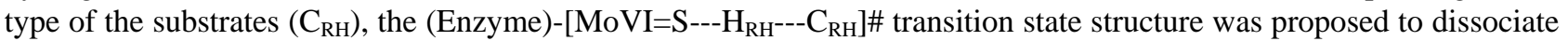
into $\mathrm{O}-\mathrm{C}_{\mathrm{R}}$ and (Enzyme) $[\mathrm{MoVI}=\mathrm{O}(=\mathrm{S})(-\mathrm{OH})]$ without forming a stable intermediate or by forming an (Enzyme)-[MoIV-O- $\left.\mathrm{C}_{\mathrm{R}}\right]$ intermediate.

\section{Catalvsis stage}

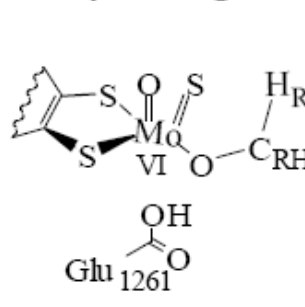

a
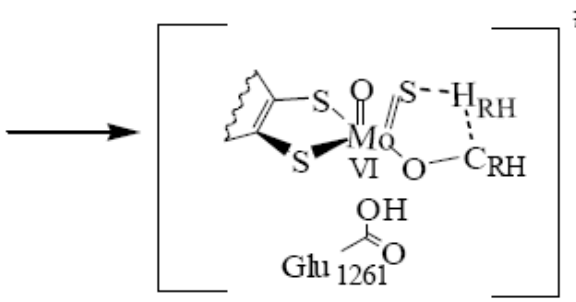

$\mathrm{b}$
\#

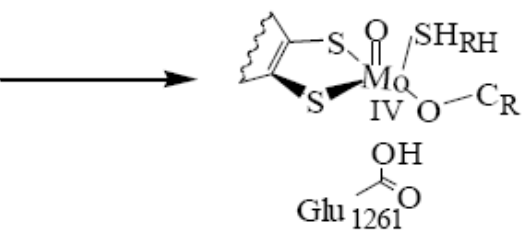

$\mathrm{c}$

Scheme1.1. A hypothetical schematic model, representing the catalytically crucial elements of the reductive-half reaction, for the hydroxylation of substrates $(\mathrm{CRH}$,$) by b m \mathrm{XOR}$ enzymes

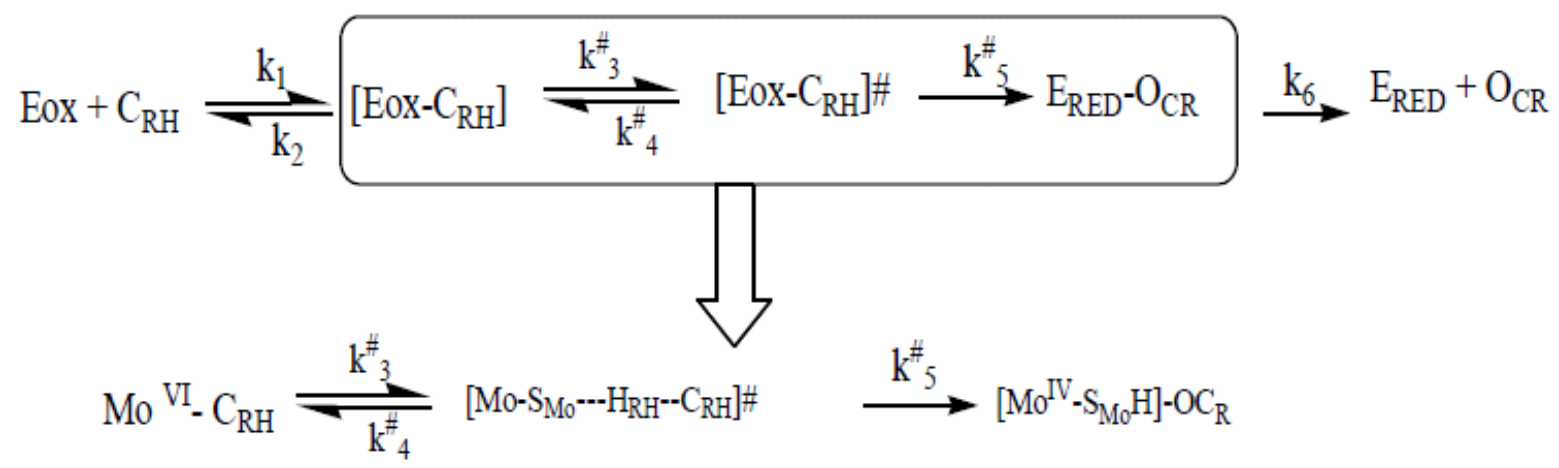

Scheme 1.2. A hypothetical description for the transition state structure that involved the transfer of substrate proton $\left(\mathrm{H}_{\mathrm{RH}}\right)$ from $\mathrm{C}_{\mathrm{RH}}$ to $\mathrm{S}_{\mathrm{MO}}$

A transition state structure is the molecular species that is represented by the top of the potential energy curve in a simple one-dimensional reaction coordinate diagram [Senthilkumar and Kolandaivel, (2003)]. The energy of this species is needed in order to determine the activation energy of the reaction and thus the reaction rate. It is a distinct species in the reaction coordinate that determine the absolute reaction rate. 
From spectroscopic studies, it is suggested that the molybdenum center cycles through three oxidation states (VI, V, IV) [Senthilkumar and Kolandaivel, (2003) and Ilich and Hille, (1999)]. Even though the transition state structure is central to understanding catalysis, no transition state structures have been established to date [Senthilkumar and Kolandaivel, (2003)]]. Understanding how enzymes work and modeling enzymatic transition state provide an understanding of catalysis, and permit the design of inhibitors [Schramm, (1998)]. But, modeling the transition state structure can't be achieved by any modern practical method due to its very small half-life [Schramm, (1998)]. The transition state for chemical reactions is proposed to have lifetimes near $10-13 \mathrm{sec}$, the time required for a single bond vibration [Schramm, (1998)]. No physical or spectroscopic method is available to directly observe the structure of the transition state for enzymatic reactions [Schramm, (1998)]. However, modeling and understanding the nature of the transition state is a key in probing the reaction mechanism for different chemical and biochemical transformations [Ayala and Schlegel, (1997)]. Understanding if catalysis is substrate dependent is a key factor in catalysis. Also identifying whether the transition state structure occurs at a late or an early transition state is a key factor in understanding whether the transition state structure resembles the substrate or the product [Alfaro and Jones, (2008), and Ayala and Schlegel, (1997)]. Therefore, computation chemistry is expected to play a role in providing insight on the nature of the transition state by providing parameters like bond order and bond distance. It also shows the transition state structure with its full geometry which can't be achieved by any other chemical or biochemical techniques.

\subsection{Effect of Substituent Groups on the Transition State Structure}

The nucleic acid bases are interesting compounds due to their biochemical, pharmacological, chemical and physiochemical importance. Substitution of thio and seleno groups to the nucleic acid bases makes it more interesting compound due to its mutation properties of biological importance and pharmacological point of view [Dinesh, Shikha, Bhavana, Nidhi, Dileep, (2010) and Kim, Jang, Cho and Hwang, (2010)]. The thio derivatives also belong to a family of t-RNA with a potential application in the drug industry [Senthilkumar and Kolandaivel, (2003)]]. Thus, a number of analogues of nucleic acid bases have been the target of extensive studies because of their importance in many biological studies. But, relative to oxo substituted, the thio and seleno substituted purine derivatives are less studied [Civcir, (2001)]. The oxygen of both purine and pyrimidine bases is substituted with sulfur, selenium, or methyl to produce an important class of analogues [Kim, Jang, Cho and Hwang, (2010)]. For example, thio substituted guanine derivative 2-amino-6-thiopurine (2A6TP) has interesting chemotherapy effects, including powerful antitumoral activity [Civcir, (2001)].]. The nature of the transition state for XO is expected to be substrate dependent and anticipates the Hammond principle [Alfaro and Jones, (2008)]. The Hammond postulate predicts that transition state structure resembles more like reactant with faster reaction rates [Alfaro and Jones, (2008)]. In addition, the affinity of the enzyme towards different reducing substrate differs from substrate to substrate. The electronic nature of substituent found in the geometry of the substrate to be hydroxylated plays a role for the enzyme to show different affinity towards different reducing substrates [Alfaro and Jones, (2008)].

In general, the parametric changes are shown to dictate the position of HRH at the transition state. Along the reaction pathway, depending on the nature and type of substrates, the transition states are proposed to occur either during the late transition state (that resembled the products) or early transition state (that resembled the reactants). The Hammond postulate can be greatly influenced by the nature of the substrate which is suggested to influence the bond distances $\left(\mathrm{C}_{\mathrm{RH}^{-}}-\mathrm{H}_{\mathrm{RH}}, \mathrm{C}_{\mathrm{RH}^{-}} \mathrm{O}_{\mathrm{eq}}\right.$ and $\left.\mathrm{S}_{\mathrm{Mo}}-\mathrm{H}_{\mathrm{RH}}\right)$ and hence, the nature of the transition state structure [Alfaro and Jones, (2008)].

The enzyme can oxidize a wide range of substrates, so the use of chalcogen and methyl substituted purine derivatives might give an insight in probing reaction mechanism of XO. The chalcogen replacement on the pyrimidine ring is expected to affect the ability of the molecule to delocalize emerging charge during nucleophilic reaction. Therefore, the ring substitution with different electronic nature gives different insight about the nature of the interaction between the active site and reducing substrates.

Understanding the effect of chalcogen replacement, at the transition state and the behavior of purine derivatives towards xanthine oxidase, is important to alleviate the problems related to the enzyme. It also helps to understand the electronic nature of different purine derivatives. The presence of chalcogens and methyl in the geometry of the substrate, xanthine, may have a role to influence the overall electron transfer process as they exhibit different ways to distribute electron density in a molecule. The different electronic nature of oxygen, sulfur, selenium, amine group and methyl group in the structure of xanthine are also expected to affect the nature of the carbon atom to be hydroxylated and the Mo center of the active site through electron transfer process.

The chalcogens $(\mathrm{O}, \mathrm{S}$ and $\mathrm{Se})$ are expected to have different electron negativity and polarizability. This difference is expected to affect the reactivity of the geometries (Figure 2.2). However, when oxo group is substituted with methyl $\left(\mathrm{CH}_{3}\right)$ group, the nature of aromaticity is expected to be altered. The aromaticity of the parent molecule involves free electrons of two nitrogen atoms from pyrimidine and imidazole rings. Up on substitution of methyl group only a pair of free electron 
involved for aromaticity. Thus, the ability of the charge delocalization on the geometries could show variation during nucleophilic reaction. It is also expected to influence the nature of the transition state and the allocation of two electrons on the active site. In this work, the effect of chalcogen replacement and methyl group at the transition is expected to be addressed. Although the transition state structure is characterized by one imaginary negative frequency [Ayala, and Schlegel, (1997) and Contreras, Lorena and Gerli, (2008)], the imaginary negative frequencies and linear motions of the $\mathrm{H}_{\mathrm{RH}}$, at the transition state, is also proposed to vary depending on the affinity of the substrates (orientation of substrates and substrate-binding sites) [Bayse, (2009)]. The frequencies and intensities are expected to depend on the conformation and binding-sites of the substrates. The variations in the activation energy for all complexes are presumed to be due to the absence of the factors that are supposed to stabilize the charge accumulation [Bayse, (2009)].

In this work, sulfur, selenium, and methyl substituted guanine analogs are used to model the transition state structure of the active site and develop a more unified mechanism. The purpose is to identify the role of chalcogen groups at the transition state. In this work, the behaviors of structurally similar structures at the transition state are characterized to support the hypothesis that if catalysis is substrate dependent is a key factor in catalysis. Identifying whether, the transition state structure occurs at a late or an early transition state is a key factor in understanding whether the transition state structure resembles the substrate or the product [Pauff, (2008)]. This is significant to connect the rate of reaction process with structural difference. It is also applicable to understand the relationship between the rate of reaction and the stability of products.

\section{Materials and Methods}

\subsection{Materials}

Several software packages were used in order to model the transition state structures and probe a plausible reaction mechanistic route for the oxidation of guanine by xanthine oxidase. One of the two software programs that were used to sketch various structures was ChemDraw ultra 2003 version 8 (Cambrigde soft corp., cambridge, MA, U.S.A.). In addition to ChemDraw, GaussView 3.0 version 6.0 (Gaussian, inc., Pittsburgh, PA, USA) was used to build molecules, set up input files, compute bond distances, and visualize frontier orbitals. The geometries constructed using GaussView were used as input files for Gaussian ${ }^{\circledR}$ 03W software version 6.0 (Gaussian, inc., Pittsburgh, PA, USA). This program was used to perform geometry optimization, frequency, linear transit optimization scan, and single point energy calculations. The output geometries, from this program, were computed using AOMix 2011/2012 revision 6.6 (center for catalysis research and innovation, University of Ottawa, Ottawa, ON, Canada) in order to perform molecular orbital analysis and constituent of chemical fragments. Finally, Microsoft word 2007, Microsoft powerpoint 2007, and Microsoft excel 2003 and 2007 (Microsoft, inc., Redmond, Washington, USA) were used for data treatment and thesis write-up. All electronic structure calculations and data handling were performed on Dell computer Optiplex780 model, 2011 (Dell, Inc., Wilhie Sdh Bhd., Penang, Malaysia).

\subsection{Methods}

\subsubsection{Computation Details}

Electronic structure calculations were performed by applying Density Functional Theory (DFT) employing B3LYP [Chowdhry, Robert, Stephen, and Dines, (2007)] (Beeke 3 parameter method for calculating the molecular energy due to overlapping orbital plus Lee-Yang Parr method of accounting electron correlation) level of theory. The calculations were performed on the truncated form of the active site (Fig. 2. 1, upper left panel) bound to guanine (Fig. 2. 1, upper right panel), as shown in Figure (2.1, lower panel).

1. The 6-31G (d', p') basis set with polarization and diffuse functions was applied for non-metal atoms (C, H, O, N, S, and Se). Similarly, the LANL2DZ (Los Alamos National Laboratory 2-Double-zeta) basis set and LANL2 effective core potential were applied for Mo atom [Chowdhry et al., 2007]. The geometries developed using GaussView were used as input files for the geometry optimization. The optimized geometries were also used as input files for single point energy calculation. In all calculations (linear transit scans, geometry optimization, frequency, transition states search, and single point energy) the "\# b3lyp gen pseudo=read \#p gfinput pop=full gfprint" key words and general job type [Foresman, J.B., (1993)] were used. In all calculations, the general job type and key words were used by applying other key words relevant to the respective calculations. During the electronic structure calculation, the runs were aborted many times due to electric power outage and other errors. In such events, calculations were resumed using the keyword "Opt=restart". This keyword was used to restart the calculation when the electronic structure calculations were interrupted. The calculations that required constraints on the coordinates, the "Opt=modredundant" keyword was used [According to Gaussian 03 versions 6.0 manual F1 option]. For similar interruption the "\# opt=(restart, modredundant) keyword was used. 

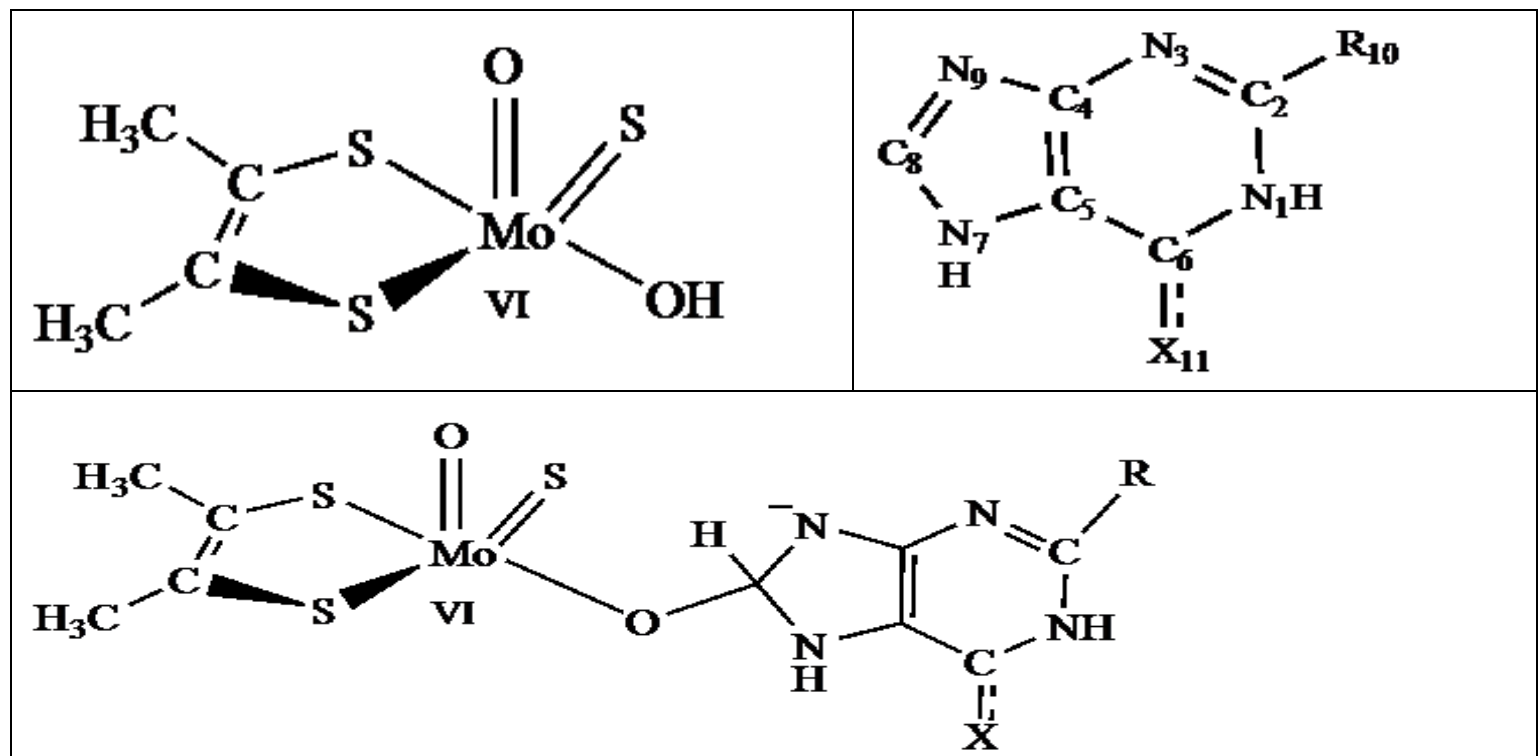

Figure 2.1. The truncated analogue for the reductive half-reaction active site structure of xanthine oxidase (upper left panel) bound to guanine derivatives (upper right panel), as shown in the (lower panel)

The structure shown in upper right panel represents guanine derivatives depending on the substituent group (X) and (R). Thus, if $(\mathrm{X})$ is substituted with oxygen and $(\mathrm{R})$ is the amino group, the structure was guanine (2AX). The derivatives for guanine were generated by maintaining $(\mathrm{R})$ to be $\mathrm{NH}_{2}$ and varying $(\mathrm{X})$ with ' $\mathrm{S}$ ' (2-amino-6-thiopurine, 2A6TP), 'Se' (2-amino-6-selenopurine, 2A6SP) and ' $\mathrm{CH}_{3}$ ' (2-amino-6methylpurine, 2A6MP).

\subsection{Modeling and Characterizing the Transition State Structures}<smiles>Nc1nc2nc[nH]c2c(=O)[nH]1</smiles>

2AX<smiles>Nc1nc2nc[nH]c2c(=S)[nH]1</smiles>

2A6TP<smiles>Nc1nc2nc[nH]c2c(=[Se])[nH]1</smiles>

2A6SP<smiles>Cc1nc(N)nc2nc[nH]c12</smiles>

2A6MP

Figure 2.2. The structures used to model and characterize the transition state structures for guanine analogues

The abbreviation are 2AX (2-amino xanthine), 2A6TP (2-amino-6-thiopurine), 2A6SP (2-amino-6-selenopurine) and 2A6MP (2-amino-6methylpurine).

The transition state structure (TS) was located using a direct frequency calculation by binding the equatorial oxygen of the active site (Oeq) with $\mathrm{C}_{8}$ of the structures shown in Figure (2.2). The substrate bound active site (Fig. 2.1, lower panel) was constructed by placing the substrate " $\mathrm{H}$ or $\mathrm{H}_{\mathrm{RH}}$ " in the middle between active site sulfido terminal (" $\mathrm{S}$ or $\mathrm{S}_{\mathrm{Mo}}$ ") and the interaction site of the substrate or substrate carbon (" $\mathrm{C}_{\mathrm{RH}}$ "), as shown in Figure 2.3. The $\mathrm{C}_{\mathrm{RH}}$ in Figure 2.3 was substituted with the derivatives shown in Figure.2.2<smiles></smiles>

Figure 2.3. The general model structure used for the transition state structure search

The tetrahedral transition state structures were modeled by placing the substrate bound hydrogen $\left(\mathrm{H}_{\mathrm{RH}}\right)$ between the 
sulfido $\left(\mathrm{S}_{\mathrm{Mo}}\right)$ terminal and the substrate carbon $\left(\mathrm{C}_{\mathrm{RH}}\right)$ center. The $\mathrm{C}_{\mathrm{RH}}$ was substituted with the structures shown in Figure 2.2 .

In the direct frequency calculation approach, the vibration frequency of a given structure was calculated without applying any constraint. The structures were optimized by applying "opt freq" key words to the general key words and job type mentioned in sub-section 2. 2. 1. In addition to the transition state structure the two structures (pre- and post-transition state structure) were optimized. The pre-transition state structure resembles the substrate bound (close to substrate bound (Fig. 2.4, upper right panel). The post-transition state structure resembles the product bound (close to product bound) (Fig. 2.4 , upper left panel). These structures were developed from the output geometry of transition state structure by adding constraint.

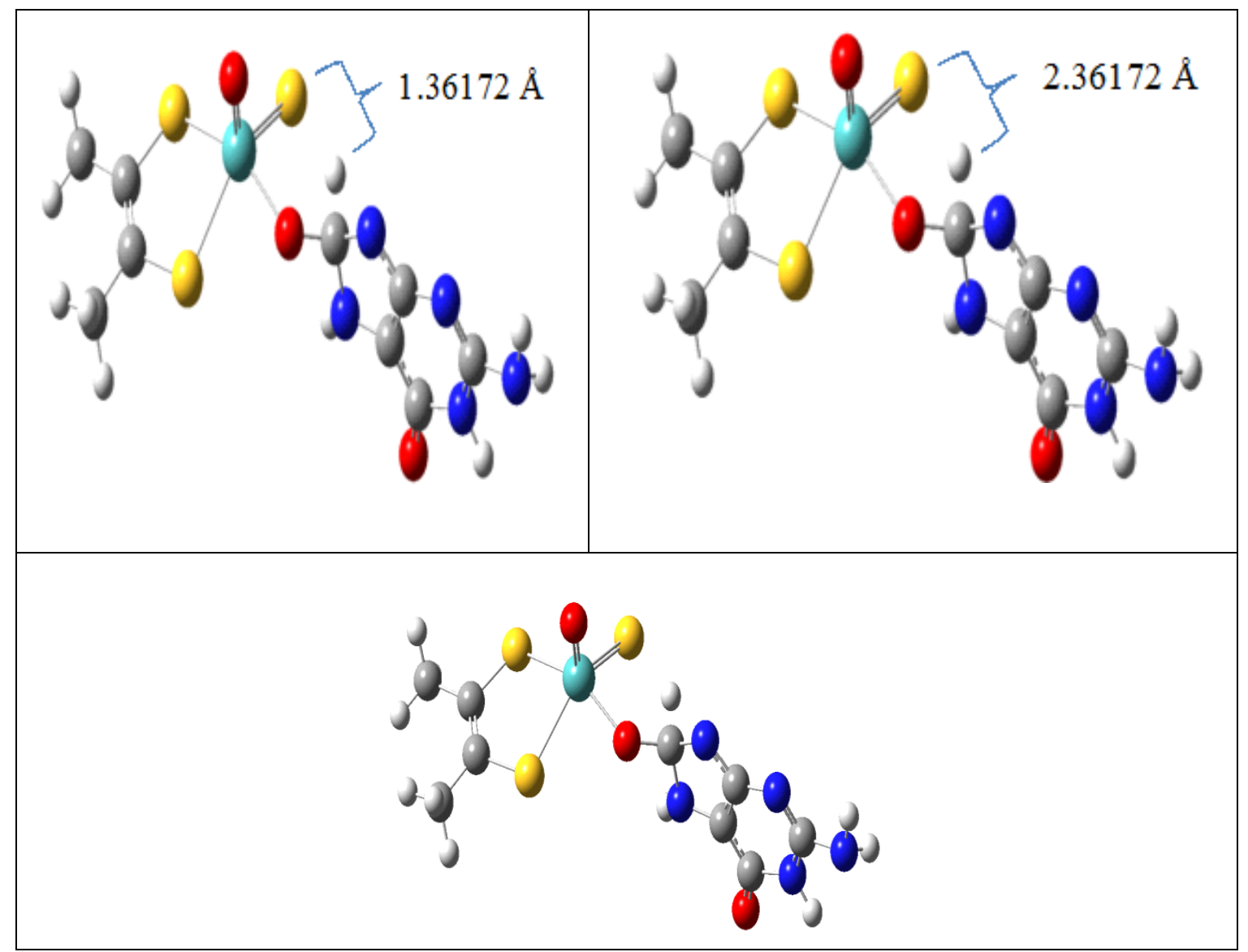

Figure 2.4. A sample input geometry for 2AX bound to the reductive half -reaction active site of xanthine oxidase enzyme, used for transition state structure characterization

The upper panels (left) and (right) were pre-transition state and post-transition state structures developed from output geometry of transition state structure (bottom panel). The input geometries for structures shown in Figure (2.2) bound the reductive half reaction of XO active site, shown in Figure (2.1), upper left panel were prepared in similar manner to this figure (Figure 2.4), as described in Figure 2.3.

The pre-transition state structure resembled substrate bound (structure close to substrate bound, but not substrate bound) where substrate hydrogen (" $\mathrm{H}_{\mathrm{RH}}$ ") was bound to the interaction site of the substrate $\left(\mathrm{C}_{8}\right.$-immidazole or " $\mathrm{C}_{\mathrm{RH}}$ ") (Fig. 2.4, upper right panel). The post-transition state structure resembled product bound where substrate hydrogen (" $\mathrm{H}_{\mathrm{RH}}$ ") $\mathrm{was}$ bound to the sulfido terminal ("S $\mathrm{S}_{\mathrm{Mo}}$ ") of the active site (Fig. 2.4, upper left panel). The two structures were optimized by adding constraint and applying "opt=moderedundant" key words to the general job type mentioned in Sub-section 2.2.1. The $\mathrm{S}_{\mathrm{Mo}}-\mathrm{H}_{\mathrm{RH}}$ bond distance coordinates were frozen to $2.26172 \AA$ and $1.36172 \AA$, respectively, for the pre- and post-transition state structures. These assumptions were made based on the typical $\mathrm{C}-\mathrm{H}$ (in methane) and $\mathrm{S}-\mathrm{H}$ (in thiol or sulfhydryl group) bond distances, respectively, $1.09 \AA$ and $1.35 \AA$. The structures represented by $\mathrm{CH}$ (pre-transition state) and SH (post-transition state), respectively, were found between the normal carbon-hydrogen and sulfur-hydrogen bond distances $(1.09 \AA)$ and $(1.35 \AA$ ). The geometry optimization of three structures $(\mathrm{CH}, \mathrm{TS}$ and $\mathrm{SH})$ were used to locate the transition state structures. All calculations were carried out at (VI) oxidation state for Mo $\left(\mathrm{Mo}^{\mathrm{VI}}\right.$ ) and constant charge and multiplicity, respectively, whole numbers (-2) and (1). The values were calculated from the negative charge around Mo 
and its oxidation state or number of unpaired electrons. Several qualitative and quantitative data were generated from the optimized structures such as total electronic energy, Mulliken atomic charge, bond distance, and frontier orbitals. The output geometry from optimized structures was used as input geometry for single point energy calculations, with the same charge and multiplicity. The outputs from the single point energy calculations were used as input files for AOMix calculation in order to generate percent contribution of chemical fragments, bond orders, and band gap energies.

\section{Result and Discussion}

\subsection{Transition State Modeling and Characterization}

In order to model the transition state structures, a series of geometry optimizations were performed at DFT/B3LYP level. From the optimized geometries, several parameters such as the total electronic energies, frequencies, bond order indices, bond distances, percent contributions of chemical fragments, and wave function descriptions were assembled, to characterize the transition state structures for the chalcogen and methyl substituted geometries.

\subsection{Predicting the Transition State Structure Based on the Total Energy and Frequency}

The structures shown in Figures (2.1, right upper panel and 2.2) were bound to the truncated form of the active site structure (Fig. 2.1, upper left panel) as shown in Figure (2.1, lower panel and 2.3) and optimized at DFT/B3LYP level. The total electronic energies on pre- $(\mathrm{CH})$, post- $(\mathrm{SH})$ and transition state (TS) structures were collected and plotted against the reaction coordinates as shown in Figure (3.1).

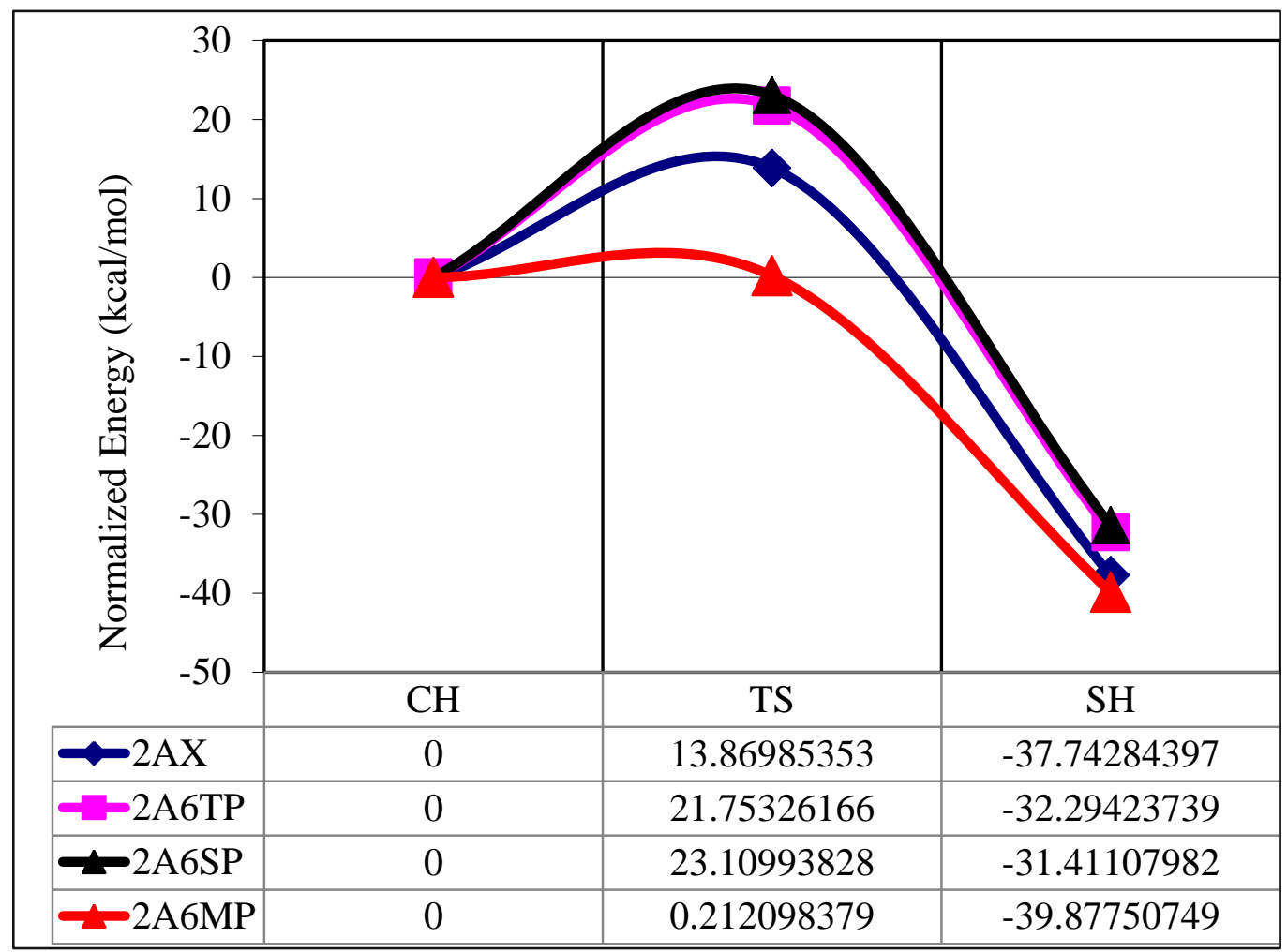

Figure 3.1. The normalized energy plot for guanine (2AX) and its substituted analogs 


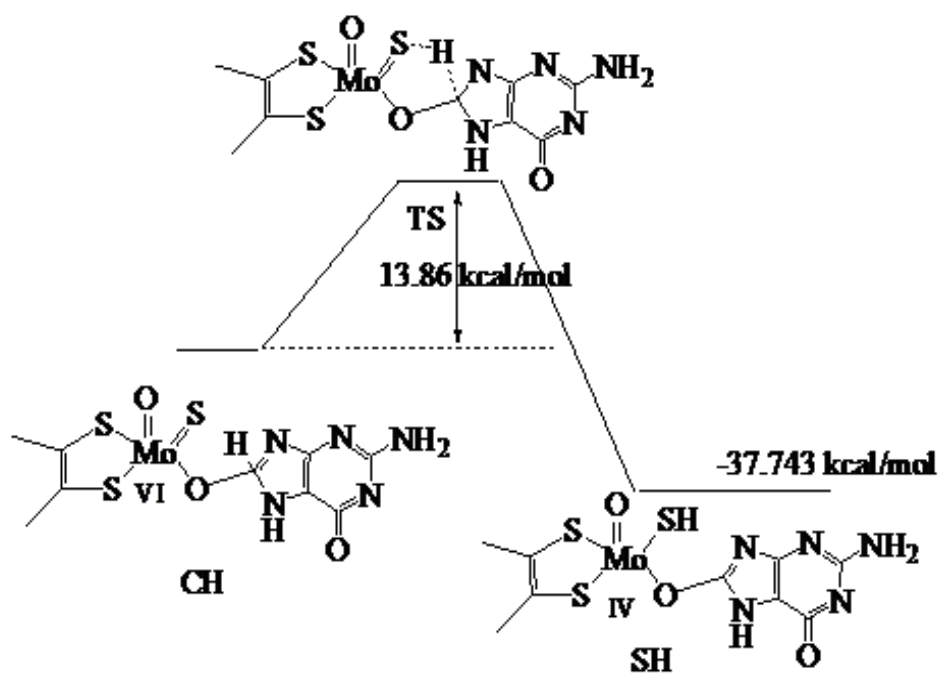

Figure 3.2. A sample reaction coordinates, for the reductive half reaction of guanine bound to xanthine oxidase enzyme

The energy profile for guanine analogs bound to XO enzyme were examined as shown in Figure 3.2. Thus, the highest energy gap $\left[\Delta \mathrm{H} \#\left(\mathrm{E}_{\mathrm{TS}}-\mathrm{E}_{\mathrm{CH}}\right)\right]$ between the energies of pre-transition state $(\mathrm{CH})$ and transition state structures (TS) was observed for the reaction coordinate of Eox-2A6SP $(23.109 \mathrm{kcal} / \mathrm{mol})$. Whereas, the lowest energy at the transition state (TS) was observed for the reaction coordinates of $2 \mathrm{~A} 6 \mathrm{MP}(0.212 \mathrm{kcal} / \mathrm{mol})$ bound to the reductive half reaction active site of xanthine oxidase (Eox-2A6MP), as shown in Figure 3.1. The minimum energy was due to the charge delocalization at the transition state. The reason for the charge delocalization was the highest partial negative charge developed at $\mathrm{N}_{7}$ immidazole ring and $\mathrm{C}_{8}$ of the molecule. The accumulation of the highest partial negative charge at $\mathrm{N}_{7}$ and $\mathrm{C}_{8}$ of immidazole was due to the shifting of bond pair electrons from adjacent $\mathrm{C}_{8}$ carbon and the flow of electrons due to the inductive effect created by methyl group, respectively. Generally, the energy at the TS for the 2AX analogs were 0.212 $\mathrm{kcal} / \mathrm{mol}$ (Eox-2A6MP), $13.869 \mathrm{kcal} / \mathrm{mol}$ (Eox-2AX), $21.753 \mathrm{kcal} / \mathrm{mol}$ (Eox-2A6TP), and 23.109 kcal/mol (Eox-2A6SP). The lowest energy at transition state for Eox-2A6MP indicated the ease for 2A6MP to enter the transition state and create a thermodynamically favorable reaction. The difference in energy $(\Delta \mathrm{H} \#)$ at TS indicated that the effect of chalcogen and methyl replacement was due to the ability of the inductive effect $\left(\mathrm{CH}_{3}\right)$ on charge delocalization. The replacement of chalcogen and methyl group at $\mathrm{C}_{6}$-pyrimidine of guanine was shown to affect the interaction site. In this work, the ability of the substrate to stabilize the emerging charge was determined by the nature of the substituent groups. The capacity of the charge stabilization of different molecules was also the reason for geometries to have different reaction rates and activation barriers.

In this work we have derived a formula which can relate turnover rate with enthalpy as:

$$
k_{c a t}=e^{-\Delta H \#}
$$

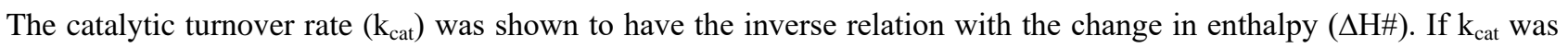
calculated from $\triangle \mathrm{H} \#$, the complex (Eox-2A6MP) with the smallest energy barrier at the transition state was expected to be converted in a very high concentration compared to the complexes with high enthalpy change. The energy obtained at the transition state was shown to clearly support the hypothesis that there would be a variation on the behavior of the transition state and reactivity upon the replacement of the chalcogen and methyl groups on the carbon $\left(\mathrm{C}_{6}\right)$ of pyrimidine ring. Thus, the highest energy shown by 2A6SP substrate indicated that the substrate had the least ability to delocalize the emerging charge at the transition state (TS). This is due to the highest polarizability of selenium compared to other substituent groups $\left(\mathrm{CH}_{3}, \mathrm{O}\right.$ and $\left.\mathrm{S}\right)$. The mobility of the electron cloud (polarizability) was due to the ability of the electron distribution to change temporarily and increase down the group of the periodic table. This was due to an increase in atomic size. The -electrons were more polarizable than the $\sigma$-electrons. Thus the maximum mobility of the electron cloud in Eox-2A6SP was due to the presence of $\pi$-electrons, in addition to high atomic size of selenium. Whereas, the mobility of electron cloud in methyl substituted guanine analog, Eox-2A6MP was minimum rather high charge accumulation was preferred through inductive effect. According to the data, the polarizable substituents were expected to slow down the reaction. On the other hand, the electron donating substituents (such as methyl group) were expected to speed up the reaction of $\mathrm{XO}$ by stabilizing the transition state structure. The highest activation barrier for Eox-2A6SP also revealed the lowest reduction potential of the metal. 
In addition to the energies at the transition state, the energies for the post-transition state structure (the structure near to the product bound, SH) were collected. The energies at SH for the structures bound to the active site were $-39.87 \mathrm{kcal} / \mathrm{mol}$, $-37.74 \mathrm{kcal} / \mathrm{mol},-32.29 \mathrm{kcal} / \mathrm{mol}$ and $-31.41 \mathrm{kcal} / \mathrm{mol}$ for (Eox-2A6MP), (Eox-2AX), (Eox-2A6TP), (Eox-2A6SP), respectively. The release of such energy in an exothermic manner revealed that the structures were thermodynamically more stable compared to the substrate bound structures $(\mathrm{CH})$. Even though all substrates were converted in to their post-transition state exothermically, the highest exothermicity was observed in the presence of substrates with methyl group substitution $(-39.87 \mathrm{kcal} / \mathrm{mol})$. The highest exothermicity was due to the high interaction between the active site and substrate (2A6MP). Therefore, Eox-2A6MP could be easily converted in to product with minimum activation barrier and considerably large exothermicity. The product obtained from the reaction involving Eox-2A6SP (2-amino-6-selenouric acid) was destabilized by $8.46 \mathrm{kcal} / \mathrm{mol}$ relative the most stable product, 2A6MP bound (2-amino-6-methyluric acid). The experimental work by Kalra et al, 2007 showed that the presence of 2A6SP (2-amino-6-selenopurine) as a substrate was claimed to a preferential inhibitor for XO. Even though, there is no experimental data reported in the presence of 2A6TP, the theoretical work was shown to reveal a small energy difference $(2 \mathrm{kcal} / \mathrm{mol})$. As a result, 2A6TP could be a potential inhibitor. Thus, the highest activation energies reported in the presence of the two substrates (2A6TP and 2A6SP) at the transition state (Figure 3.1) were expected to be due to their inhibition activity when reacted with the enzyme.

The potential energy surface diagram, shown in Figure 3.1, revealed that the total energies obtained in the presence of all substrates, at the transition state, was closer to the energy of the structure near to substrate bound structure $(\mathrm{CH})$. According to the Hammond's principle, the position of all transition state structures was found to be early transition state. According to the Hammond postulate, the transition state structure was expected to be more reactant like with faster reaction rate [Alfaro, and Jones, (2008)]. However, the position of the transition state structure for Eox-2A6MP was found to be product like relative to the transition structures located in the presence of chalcogen substituted guanine analogs. This is inconsistent with Hammond principle, and the anti-Hammond effect is consistent with inductive effect enhancing the rate of tetrahedral transition state formation. Potentially this might show an effect on the allocation of two electrons. The finding clearly point out the effect of electron donating groups through resonance $(\mathrm{O}, \mathrm{S}$ and $\mathrm{Se})$ and through inductive effect $\left(\mathrm{CH}_{3}\right)$. Methyl and amine group substituted purines were shown to be more reactive than the chalcogen and amino group substituted purines. This was due to the charge stabilization at transition state that was favored by inductive effect and localization of the electron cloud around a single atom. In summary, the results obtained from the total electronic energy was shown to confirm the highest reactivity and product stability for the methyl substituted analog, early transition state structure for oxo, thio and seleno substituted guanine analogs, product like transition state structure for methyl substituted analog, different reduction potential of the metal, and potential inhibition of XO by 2A6TP and 2A6SP.

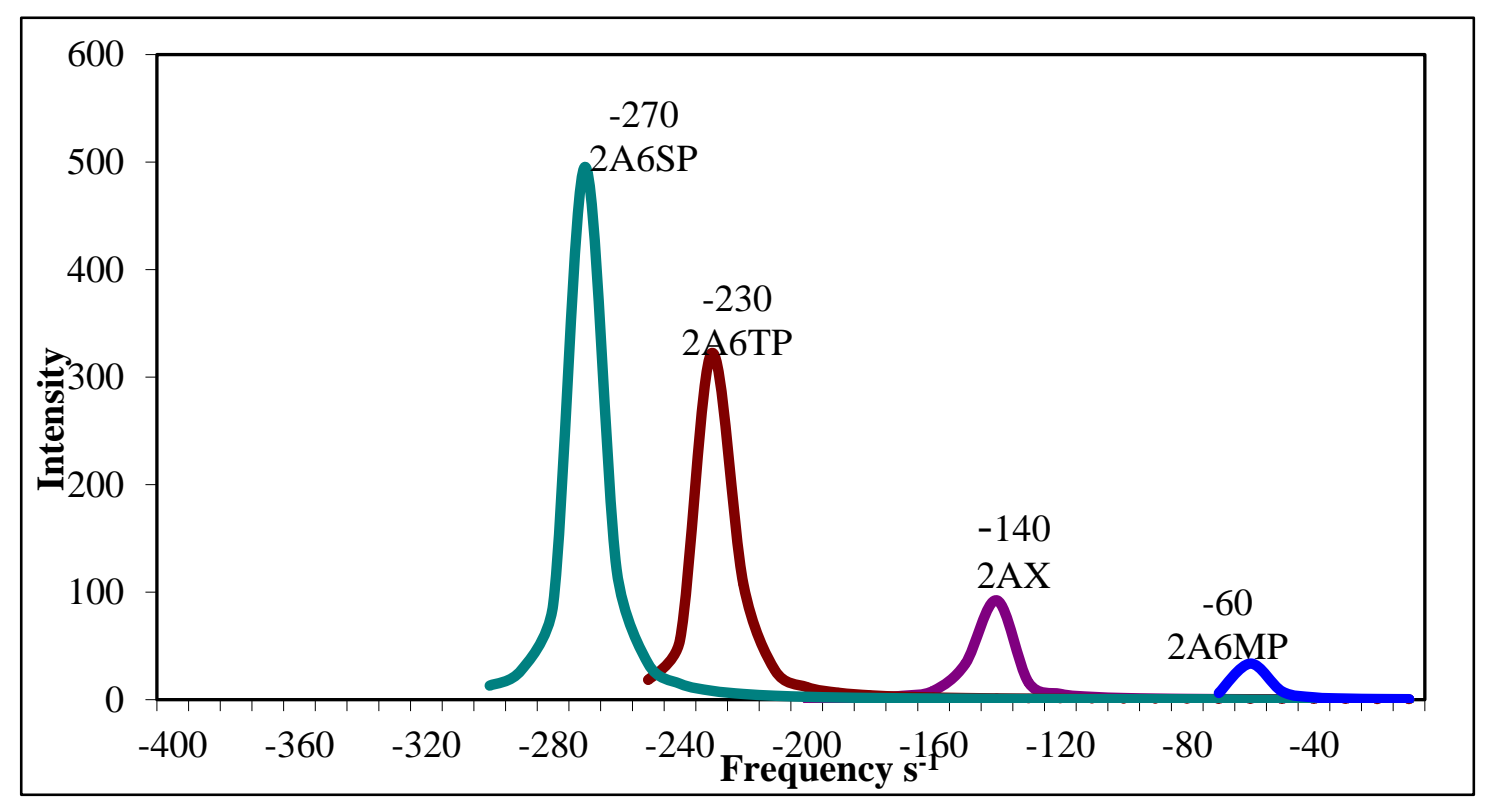

Figure.3.3. The frequency values used to characterize the transition state geometries through the presence of one negative imaginary frequency

The imaginary negative frequencies obtained from the substrates bound to the truncated reductive-half reaction active site were shown in Figure (3.3) and Table (3.1). From 2AX derivatives, the highest vibrational frequencies were observed on 
methyl $\left(\mathrm{CH}_{3}\right)$ substituted analogs. This indicated that the time required to cross the transition state for methyl substituted analog were short as compared to silico, thio and oxo-counter parts.

Table 3.1. The data used to characterize the transition state structure obtained from linear transit scan calculation in the presence of $2 \mathrm{AX}$ derivatives

\begin{tabular}{lllllll}
\hline Structure & \multicolumn{2}{l}{ Bond distance $(\AA)$} & $\begin{array}{l}\text { Frequency } \\
\left(\mathrm{s}^{-1}\right)\end{array}$ & $\% \mathrm{Mod}_{\mathrm{xy}}$ & \multicolumn{2}{l}{ Bond order } \\
\cline { 2 - 3 } \cline { 6 - 7 } & $\begin{array}{l}\mathrm{S}_{\mathrm{Mo}}-\mathrm{H}_{\mathrm{RH}} \\
\text { distance }\end{array}$ & $\begin{array}{l}\mathrm{C}_{\mathrm{RH}}-\mathrm{H}_{\mathrm{RH}} \\
\text { distance }\end{array}$ & & & $\mathrm{S}_{\mathrm{Mo}}-\mathrm{H}_{\mathrm{RH}}$ & $\mathrm{C}_{\mathrm{RH}}-\mathrm{H}_{\mathrm{RH}}$ \\
$2 \mathrm{AX}$ & 1.86172 & 1.22676 & -142.309 & 24.14 & 0.301 & 0.657 \\
$2 \mathrm{~A} 6 \mathrm{TP}$ & 1.83274 & 1.24180 & -227.924 & 21.18 & 0.324 & 0.634 \\
$2 \mathrm{~A} 6 \mathrm{SP}$ & 1.81862 & 1.24824 & -269.000 & 20.24 & 0.336 & 0.623 \\
$2 \mathrm{~A} 6 \mathrm{MP}$ & 1.96592 & 1.19766 & -59.386 & 19.05 & 0.238 & 0.701 \\
\hline
\end{tabular}

Since frequency and time were inversely related, an imaginary negative frequency could tell us the time required to cross the transition state. The highest vibrational frequency value of Eox-2A6MP revealed that the time required to cross the energy barrier was minimal. Based on the vibrational frequency values, the $2 \mathrm{AX}$ derivatives were shown to assume the following trend: 2A6SP $<2 \mathrm{~A} 6 \mathrm{TP}<2 \mathrm{AX}<2 \mathrm{~A} 6 \mathrm{MP}$. This indicated that the Eox-2A6MP was kinetically more favorable than other chalcogen substituted structures. The frequency data revealed that the Eox-2A6SP required more time to cross the energy barrier. This was consistent with the ability of the substrate to inhibit XO. In prior study [Kalra et al, 2007] performed a toxicity experiment and suggested that the inhibitor was nontoxic. They also suggested that the inhibitors anti-cancer activity in combination with 6-Mercaptopurine [Kalra et al, 2007]. Hence, this work gives the electronic structure description of preferential inhibitor and anti-cancer drug, 2A6SP.

As shown in Table 3.1, a difference in reactivity was observed in the presence of chalcogen replaced substrates. The reactivity between oxo substituted and thio substituted structures was faster by two orders of magnitude compared to the reactivity observed in the presence of thio and seleno substituted substrates. The total electronic energy data also revealed small difference between thio and seleno substituted substrates. This indicated the periodic trend shared by the two atoms or the small difference experienced by the atoms. Based on the data, the frequency value was in line with the energy barrier obtained from linear transit scan Figure 3.1. In addition to frequency data, bond distances $\left(\mathrm{S}_{\mathrm{Mo}}-\mathrm{H}_{\mathrm{RH}}\right.$ and $\left.\mathrm{C}_{\mathrm{RH}}-\mathrm{H}_{\mathrm{RH}}\right)$ were also computed at the transition state using Gauss View software package. As the observed bond distances reported in Table 3.1 revealed, at the transition state, the substrates with oxo, thio and seleno substitution revealed a decrease in $\mathrm{S}_{\mathrm{Mo}}-\mathrm{H}_{\mathrm{RH}}$ bond distance and an increase in $\mathrm{C}_{\mathrm{RH}}-\mathrm{H}_{\mathrm{RH}}$ bond distance. Whereas, the maximum $\mathrm{S}_{\mathrm{Mo}}-\mathrm{H}_{\mathrm{RH}}$ bond distance $(1.96592 \AA)$ and minimum $\mathrm{C}_{\mathrm{RH}}-\mathrm{H}_{\mathrm{RH}}$ bond distance $(1.19766 \AA)$ were reported for Eox-2A6MP at the transition state structure. The data revealed the direct relation between $\mathrm{S}_{\mathrm{Mo}}-\mathrm{H}_{\mathrm{RH}}$ bond distance and vibrational frequency value. In addition, the data supported the inverse relation between peak intensities (Figure 3.3) and $\mathrm{S}_{\mathrm{Mo}}-\mathrm{H}_{\mathrm{RH}}$ bond distance. As a result, the intensity of the peak had a direct relation with the speed of vibration observed for hydrogen atom at the transition state. The computation data revealed the preferential non-toxic inhibitor for XO enzyme. In addition, the relative kinetic and thermodynamic stabilities of selected purine derivatives (2AX analogs) were reported based on the total electronic energy and vibrational frequency data. Therefore, the highest thermodynamic stability was the highest kinetically favorable the reaction.

\subsection{Characterization of Transition State Structure Using Bond Order, Bond Distance, Mulliken Atomic Charge and Wave Function}

The bond order for $\mathrm{C}_{\mathrm{RH}}-\mathrm{H}_{\mathrm{RH}}$ bond decreased as $\mathrm{H}_{\mathrm{RH}}$ migrated from $\mathrm{C}_{\mathrm{RH}}$ to $\mathrm{S}_{\mathrm{Mo}}$ at the transition state, Table 3.2. Whereas, the bond order for $\mathrm{S}_{\mathrm{Mo}}-\mathrm{H}_{\mathrm{RH}}$ increased as $\mathrm{H}_{\mathrm{RH}}$ migrated from $\mathrm{C}_{\mathrm{RH}}$ to $\mathrm{S}_{\mathrm{Mo}}$. This indicated that the breaking and formation of $\mathrm{C}_{\mathrm{RH}}-\mathrm{H}_{\mathrm{RH}}$ and $\mathrm{S}_{\mathrm{Mo}}-\mathrm{H}_{\mathrm{RH}}$ bonds, respectively, at the transition state.

Table 3.2. The bond order for $\mathrm{C}_{\mathrm{RH}}-\mathrm{H}_{\mathrm{RH}}$ and $\mathrm{S}_{\mathrm{Mo}}-\mathrm{H}_{\mathrm{RH}}$ of $2 \mathrm{AX}$ analogs at the transition state (TS)

\begin{tabular}{lll}
\hline structure & $\mathrm{C}_{\mathrm{RH}}-\mathrm{H}_{\mathrm{RH}}$ & $\mathrm{S}_{\mathrm{Mo}}-\mathrm{H}_{\mathrm{RH}}$ \\
\hline $2 \mathrm{AX}$ & 0.657 & 0.301 \\
$2 \mathrm{~A} 6 \mathrm{TP}$ & 0.634 & 0.324 \\
$2 \mathrm{~A} 6 \mathrm{SP}$ & 0.623 & 0.336 \\
2A6MP & 0.701 & 0.238
\end{tabular}

The $\mathrm{C}_{\mathrm{RH}}-\mathrm{H}_{\mathrm{RH}}$ bond order was shown to decrease as we go from oxo to seleno substituted geometry at the transition state 
and the converse was true for $\mathrm{S}_{\mathrm{Mo}}-\mathrm{H}_{\mathrm{RH}}$ bond order as shown in Table 3.2.

The bond order for $\mathrm{C}_{\mathrm{RH}}-\mathrm{H}_{\mathrm{RH}}$ are 0.657 (43.6\%), 0.634 (42.7\%) and $0.623(42.38 \%)$, respectively, at the transition state, for oxo, thio and seleno substituted geometries, as shown in Table 3.3. The bond order difference for $\mathrm{C}_{\mathrm{RH}}-\mathrm{H}_{\mathrm{RH}}$ bond order between pre- transition state and transition state were $12 \%, 14 \%, 15 \%$, respectively, for oxo, thio and seleno substituted geometries. Whereas, the bond order differences between the transition state and post-transition state were $44 \%, 42 \%$ and $42 \%$, respectively, for oxo, thio and seleno substituted geometries. This indicates that the nature of $\mathrm{C}_{\mathrm{RH}}-\mathrm{H}_{\mathrm{RH}}$ bond order was closer to pre transition state structure for all three geometries.

Table 3.3. The bond order profile for $2 \mathrm{AX}$ analogs along the reaction coordinates

\begin{tabular}{lllllllllllll}
\hline Bond & $2 \mathrm{AX}$ & \multicolumn{3}{c}{ 2A6TP } & \multicolumn{3}{c}{ 2A6SP } & \multicolumn{3}{c}{ 2A6MP } \\
Order & $\mathrm{CH}$ & $\mathrm{TS}$ & $\mathrm{SH}$ & $\mathrm{CH}$ & $\mathrm{TS}$ & $\mathrm{SH}$ & $\mathrm{CH}$ & $\mathrm{TS}$ & $\mathrm{SH}$ & $\mathrm{CH}$ & $\mathrm{TS}$ & $\mathrm{SH}$ \\
\hline Mo-Oeq & 1.234 & 1.054 & 0.655 & 1.176 & 1.022 & 0.634 & 1.167 & 1.014 & 0.634 & 1.19 & 1.085 & 0.652 \\
Oeq- $\mathrm{C}_{\mathrm{RH}}$ & 1.028 & 1.25 & 1.814 & 1.176 & 1.314 & 1.864 & 1.126 & 1.329 & 1.874 & 1.122 & 1.249 & 1.824 \\
$\mathrm{C}_{\mathrm{RH}}-\mathrm{H}_{\mathrm{RH}}$ & 0.844 & 0.657 & 0.003 & 0.845 & 0.634 & 0.003 & 0.845 & 0.623 & 0.002 & 0.827 & 0.701 & 0.002 \\
$\mathrm{~S}_{\mathrm{Mo}}-\mathrm{H}_{\mathrm{RH}}$ & 0.083 & 0.301 & 1.049 & 0.077 & 0.324 & 1.048 & 0.077 & 0.336 & 1.046 & 0.088 & 0.238 & 1.05
\end{tabular}

Methyl substituted geometry (Eox-2A6MP) was shown to exhibit maximum $\left(\mathrm{C}_{\mathrm{RH}}-\mathrm{H}_{\mathrm{RH}}, 0.701\right)$ and minimum $\left(\mathrm{S}_{\mathrm{Mo}}-\mathrm{H}_{\mathrm{RH}}\right.$, 0.238 ) bond orders at the transition state. The $\%$ difference in bond order for $\mathrm{C}_{\mathrm{RH}}-\mathrm{H}_{\mathrm{RH}}$ bond at the pre- and post-transition state structure with respect to the transition state structure, respectively, were $8 \%$ and $46 \%$. On the other hand, for $\mathrm{S}_{\mathrm{Mo}}-\mathrm{H}_{\mathrm{RH}}$ bond at the pre- and post-transition state structure from transition state structure were observed as $10 \%$ and $59 \%$, respectively. Relative to the chalcogen substituted geometries, the nature of $\mathrm{C}_{\mathrm{RH}}-\mathrm{H}_{\mathrm{RH}}$ and $\mathrm{S}_{\mathrm{Mo}}-\mathrm{H}_{\mathrm{RH}}$ bond orders at the transition state were maximum (46\%) and minimum (17\%), respectively. This indicated that the $\mathrm{C}_{\mathrm{RH}}-\mathrm{H}_{\mathrm{RH}}$ bond breaking and $\mathrm{S}_{\mathrm{Mo}}-\mathrm{H}_{\mathrm{RH}}$ bond formation for $2 \mathrm{~A} 6 \mathrm{MP}$ were expected to take place after the transition state. Similar to the energy barrier, the bond order also revealed that the nature of the transition state structure for $2 \mathrm{~A} 6 \mathrm{MP}$ was product like compared to the other geometries that showed early transition state structure.

The bond order for Mo-Oeq and Oeq- $\mathrm{C}_{\mathrm{RH}}$ were decreased and increased, respectively, by $20 \%$ and $19 \%$, as the $\mathrm{H}_{\mathrm{RH}}$ migrated from the substrate $\left(\mathrm{C}_{8}\right)$ to the active site terminal sulfido $\left(\mathrm{S}_{\mathrm{Mo}}\right)$. On the other hand, the bond order for Mo- $\mathrm{S}_{\mathrm{Mo}}$ and $\mathrm{S}_{\mathrm{Mo}}-\mathrm{H}_{\mathrm{RH}}$ were decreased and increased, respectively, by $18 \%$ and $66 \%$, up on the migration of hydrogen. The percent bond order data for Mo-Oeq and Oeq- $\mathrm{C}_{\mathrm{RH}}$ bonds clearly confirmed that the breaking and formation of Mo-Oeq and Oeq- $\mathrm{C}_{\mathrm{RH}}$ bonds. This bond breaking and formation for Mo-Oeq and Oeq- $\mathrm{C}_{\mathrm{RH}}$ bonds, at the transition state was quantitatively similar. Unlike to these, the bond order change for Mo- $\mathrm{S}_{\mathrm{Mo}}$ and $\mathrm{S}_{\mathrm{Mo}}-\mathrm{H}_{\mathrm{RH}}$ as $\mathrm{H}_{\mathrm{RH}}$ migrates from $\mathrm{C}_{\mathrm{RH}}$ to $\mathrm{S}_{\mathrm{Mo}}$ was found not to be similar (18\% and $66 \%$ ). This was because the bond order for Mo-S $\mathrm{S}_{\mathrm{Mo}}$ was not bond breaking rather it was corresponds to a partial loss of the double-bond character (bond lengthening).

In addition to the bond order, various bond distances which were expected to be involved in the bond formation and bond breaking while $\mathrm{H}_{\mathrm{RH}}$ linearly migrates from $\mathrm{C}_{\mathrm{RH}}\left(\mathrm{C}_{8}\right)$ of guanine to terminal sulfido $\left(\mathrm{S}_{\mathrm{Mo}}\right)$. The bond distances of $\mathrm{C}_{\mathrm{RH}}-\mathrm{H}_{\mathrm{RH}}$, Oeq- $\mathrm{C}_{\mathrm{RH}}, \mathrm{S}_{\mathrm{Mo}}-\mathrm{H}_{\mathrm{RH}}$ and Mo-Oeq bonds for $2 \mathrm{AX}$ analogs at transition state were shown in Table 3.4. The substituent $\mathrm{R}$ (at $\mathrm{C}_{6}$ ) stands for $\mathrm{O}, \mathrm{S}, \mathrm{Se}$ and $\mathrm{CH}_{3}$ groups keeping the amine (at $\mathrm{C}_{2}$ ) constant for $2 \mathrm{AX}$ analog, as described in Figure 2.1.

Table 3.4. Transition state bond lengths and activation enthalpies for substituted $2 \mathrm{AX}$ analogs. The bond distances are expressed in angstrom $(\AA)$

\begin{tabular}{llllll}
\hline $\mathrm{R}$ & $\mathrm{C}_{\mathrm{RH}}-\mathrm{H}_{\mathrm{RH}}$ & Oeq- $\mathrm{C}_{\mathrm{RH}}$ & $\mathrm{S}_{\mathrm{Mo}}-\mathrm{H}_{\mathrm{RH}}$ & Mo-Oeq & $\Delta \mathrm{H} \#(\mathrm{kcal} / \mathrm{mol})$ \\
\hline $\mathrm{O}$ & 1.22636 & 1.40185 & 1.86172 & 1.98429 & 13.869 \\
$\mathrm{~S}$ & 1.24074 & 1.37523 & 1.83274 & 1.98945 & 21.753 \\
$\mathrm{Se}$ & 1.24836 & 1.37046 & 1.81862 & 1.99332 & 23.109 \\
$\mathrm{CH}_{3}$ & 1.19766 & 1.39728 & 1.96592 & 1.97015 & 0.212
\end{tabular}

As described in Table (3.4), the bond distance for $\mathrm{C}_{\mathrm{RH}}-\mathrm{H}_{\mathrm{RH}}$ at the transition state increased from oxo to seleno. The minimum $\mathrm{C}_{\mathrm{RH}}-\mathrm{H}_{\mathrm{RH}}$ bond distance $(1.19766 \AA$ ) was observed for methyl substituted geometry at transition state. Maximum $\mathrm{C}_{\mathrm{RH}}-\mathrm{H}_{\mathrm{RH}}$ bond distance $(1.24836 \AA)$ with high activation enthalpy $(23.109 \mathrm{kcal} / \mathrm{mol})$ was observed for seleno substituted geometry. Whereas, minimum $\mathrm{C}_{\mathrm{RH}}-\mathrm{H}_{\mathrm{RH}}$ bond distance $(1.19766 \AA)$ with minimum activation enthalpy $(0.212 \mathrm{kcal} / \mathrm{mol})$ was shown for the methyl substituted geometry. The minimum $\mathrm{C}_{\mathrm{RH}}-\mathrm{H}_{\mathrm{RH}}$ bond distance at the transition state revealed that the hydrogen atom to be transferred from substrate carbon $\left(\mathrm{C}_{\mathrm{RH}}\right)$ to $\mathrm{S}_{\mathrm{Mo}}$ was not far from its origin. This was due to the high negative charge development on the imidazole ring $\left(\mathrm{C}_{8}\right)$ contributed from the methyl group through inductive effect, and this can induce strong carbon-hydrogen bond. The change in $\mathrm{C}_{\mathrm{RH}}-\mathrm{H}_{\mathrm{RH}}$ bond distances between the transition and 
pre-transition state was computed as $1.99 \%, 2.52 \%, 2.35$, and $1.24 \%$, respectively, for oxo, thio, seleno and methyl substituted geometries. These bond distance change suggested that the nature of $\mathrm{C}_{\mathrm{RH}}-\mathrm{H}_{\mathrm{RH}}$ bond distances were reactant like for the first three geometries. Whereas, the later transition state structure was relatively product like. The variation in bond distances, bond orders, and energies observed at the transition state, in the presence of various substrates, indicated that the enzyme and reduction potential on the metal center was substrate dependent. The bond distances of Mo- $\mathrm{O}_{\mathrm{eq}}$ at $\mathrm{CH}$, TS and SH were, respectively, $1.92289 \AA, 1.98429 \AA$ and $2.19682 \AA$. The bond distance was shown to lengthen by $0.27393 \AA$ as $\mathrm{H}_{\mathrm{RH}}$ migrates from $\mathrm{C}_{\mathrm{RH}}$ to $\mathrm{S}_{\mathrm{Mo}}$. On the contrary, the bond distance of Oeq- $\mathrm{C}_{\mathrm{RH}}$ at $\mathrm{CH}$, TS and SH were, respectively, $1.49475 \AA, 1.40185 \AA$ and $1.26121 \AA$ as hydrogen $\left(\mathrm{H}_{\mathrm{RH}}\right)$ migrated from $\mathrm{C}_{8}$ of $2 \mathrm{AX}$ to the sulfido terminal $\left(\mathrm{S}_{\mathrm{Mo}}\right)$. The bond distance was shown to shorten by $0.23354 \AA$. The bond lengthening and shortening clearly confirmed that the breaking and formation of Mo-Oeq and Oeq- $\mathrm{C}_{\mathrm{RH}}$ bonds, respectively, as hydrogen migrated from the pre- transition state to post transition state. At the transition state, the Mo-Oeq bond distance considerably lengthens to $1.98429 \AA$ by $0.05614 \AA$ and the Oeq- $\mathrm{C}_{\mathrm{RH}}$ distance was longer than that of the post transition state, $\mathrm{SH}$, by $0.2125 \AA$. Also the $\mathrm{C}_{\mathrm{RH}}-\mathrm{H}_{\mathrm{RH}}$ bond distance lengthens to $1.22636 \AA$ by $0.10579 \AA$, while the $\mathrm{S}_{\mathrm{Mo}}-\mathrm{H}_{\mathrm{RH}}$ distance was much longer than that of post transition state by $0.5 \AA$. Relative to $\mathrm{S}_{\mathrm{Mo}}-\mathrm{H}_{\mathrm{RH}}$ bond difference $(0.5 \AA)$ from post transition state, the bond distance for Oeq- $\mathrm{C}_{\mathrm{RH}}(0.2125 \AA)$ from post transition state was found to be minimum. This geometrical feature suggests that it was the oxygen atom transfer that induced the hydrogen atom transfer from substrate carbon $\left(\mathrm{C}_{8}\right.$ of $\left.2 \mathrm{AX}\right)$ to the sulfido terminal $\left(\mathrm{S}_{\mathrm{Mo}}\right)$. The shorter bond distance shown for Oeq- $\mathrm{C}_{\mathrm{RH}}$ bond might play a role for the transfer of two electrons from substrate to the active site. The $\mathrm{C}_{\mathrm{RH}}-\mathrm{H}_{\mathrm{RH}}$ bond distance was elongated from $1.12057 \AA$ to $2.94377 \AA$ unlike that of the $\mathrm{S}_{\mathrm{Mo}}-\mathrm{H}_{\mathrm{RH}}$ bond which was decreased from $2.36172 \AA$ to $1.36172 \AA$ as $\mathrm{H}_{\mathrm{RH}}$ migrated from $\mathrm{C}_{8}$ of guanine to $\mathrm{S}_{\mathrm{Mo}}$. At the transition state, the $\mathrm{C}_{\mathrm{RH}}-\mathrm{H}_{\mathrm{RH}}$ bond distance $\left(1.22636 \AA\right.$ ) was lower than $\mathrm{S}_{\mathrm{Mo}}-\mathrm{H}_{\mathrm{RH}}$ bond distance $(1.86172 \AA)$. This clearly revealed that the transition state structure was reactant like. In summary, the results obtained from bond order and bond distance revealed the presence of an early transition state for oxo, thio and seleno substituted geometries, a product like transition state for the methyl substituted geometry, a substrate dependence of xanthine oxidase activity, and an oxo transfer that induced a hydrogen transfer.

In addition to the bond distances, the wave functions of the geometries at $\mathrm{CH}$, TS and $\mathrm{SH}$ were shown in The distribution of the electron densities around chalcogen were found to increase from oxo to seleno replacement and decrease at $\mathrm{C}_{8}$, as shoun in Figure 3.4. This was due to the polarization power of the electron cloud by chalcogens. In addition, the percent molybdenum contribution for oxo, thio and seleno substituted geometries, respectively, were $24.14 \%, 21.18 \%$ and $20.24 \%$. This confirmed that the reduction potential of the metal was substrate dependant.
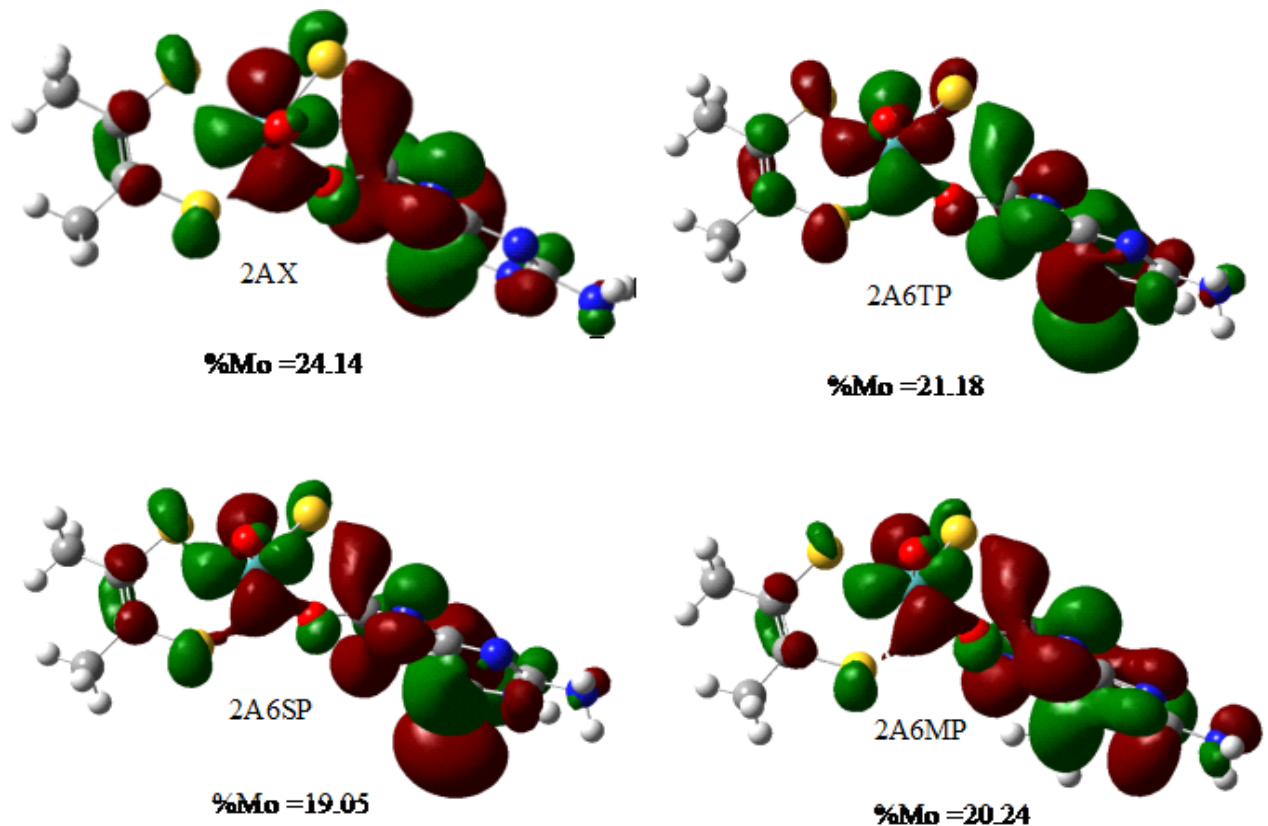

Figure 3.4. The wave function of the HOMO's obtained from the transition state structure for the oxo-2AX (upper left), thio-2A6TP (upper right), seleno-2A6SP (lower left), and methyl-2A6MP (lower right) substituted geometries

On the other hand, the methyl substituted geometry was found to have no electron density around the substituent $\left(\mathrm{CH}_{3}\right)$, rather the electron densties were found more concentrated on the interaction site $\left(\mathrm{C}_{8}\right)$ carbon. The transfer of (electron donation) from methyl through inductive effect was the main reason for the maximum electron densitiy on the interaction 
carbon. This was found to be the reason for the reaction of 2A6MP to be fast and thermodynamically more stable.

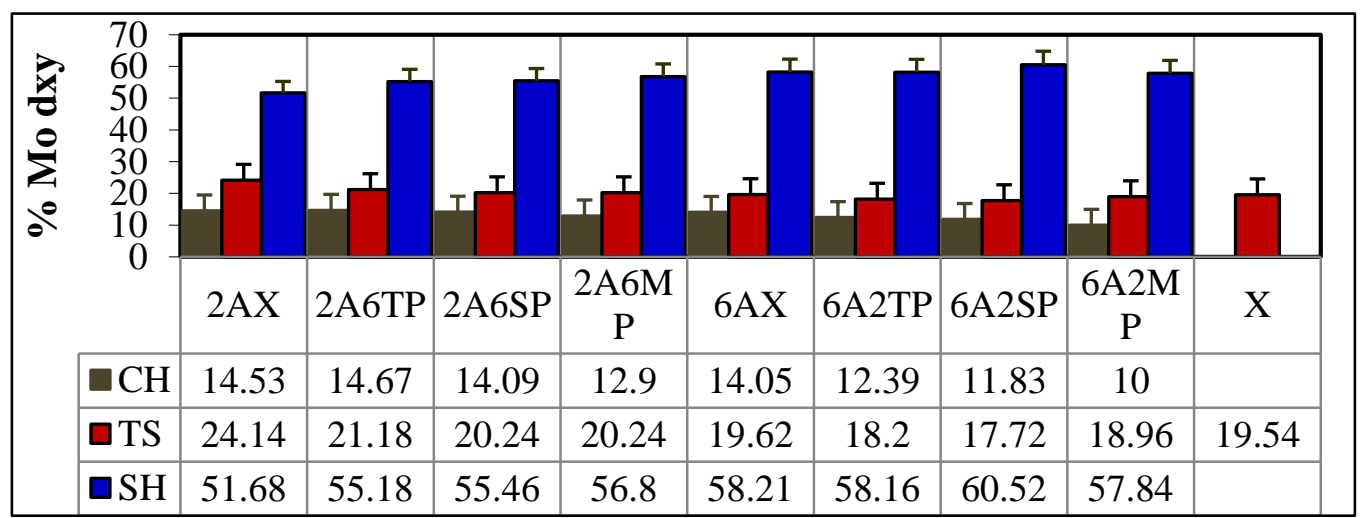

Figure $3.5 \mathrm{~A}$ plot for percent molybdenum contribution difference at homo relative to the transition state

The abbreviation X stands for the phsiological sustrate, xanthine. The percent molybdenum contribution for xanthine was obtained from reference [Haftom, 2011].

The percent $\operatorname{Mod}_{\mathrm{xy}}$ contribution of selected model substrates at the transition state was similar to that of phsyiological substrate, xanthine (X), as shown in Figre (3.5). Therefore, the spin density distribution at the transition state was almost similar. However, the rate of electron transfer was completely dependent on the nature of the substituents on the aromatic ring.

\section{Conclusion}

In the present work a DFT method and B3LYP level of theory has been employed for electronic structure calculation and quantum mechanical description of the transition state structure of guanine derivatives bound to xanthine oxidase enzyme.

The geometry optimization and frequency calculation has been performed on 2AX analogs bound to the truncated form of the reductive half-reaction active site of xanthine oxidase in order to model and characterize the transition state. The polarizability and inductive effect of the substituent, respectively, was shown to decrease and increase the reactivity of the substrate to be hydroxylated. The purine derivatives with substituents that created inductive effect was shown to stabilize the transition state structure and allowed the ease of conversion to respective products better than the remaining purine derivatives. Such types of substrates were expected to increase the rate of formation of urate crystals in the kidney. Therefore, they couldn't serve as enzyme inhibitor. On the other hand, polarizable substituent like seleno destabilizes the transition state since they were proposed to create inductive effect and resonance stabilization. Among eight model substrates used in this work, the 2A6SP and 2A6TP was found as a potential xanthine oxidase inhibitor. Following this, we concluded that purine derivatives that are substituted with polarizable substituent could serve as XO inhibitor. The reactivity of chalcogen substituted geometries decreased down a group. Therefore, it was concluded that the oxo substituted geometries were twofold more reactive than the thio and seleno substituted geometries. Relative to chalcogen substituted geometries; the methyl substituted geometry was more reactive and fast. Hence, the inductive effect was shown to play large effect in charge stabilization by creating resonance stabilization.

The total electronic energy and vibrational frequency analysis revealed that the reactions catalyzed by xanthine oxidase enzyme were kinetically and thermodynamically favorable. The natures of the transition state structure were characterized using bond order, bond distance, frequency value and total electronic energy. The natures of the transition state structures for chalcogen replaced geometries were found to be early transition state. On the other hand, the transition state structure for methyl substituted geometry was found to be product like. During the progress of the reaction, the reduction potential of the metal was shown to vary from substrate to substrate. As a result, it was concluded that the catalysis of xanthine oxidase was entirely substrate dependent.

\section{Competing Interests}

The authors declare that they have no competing interests.

\section{Authors' Contributions}

All authors had significant intellectual contribution towards the design of the study, data collection and analysis and write-up of the manuscript. Mamaru Betew conducted the experiment, analyzed the data, wrote the draft manuscript followed it up through revisions and Yilkal Bezie took part actively reviewed and edited the draft manuscript, provided comments and suggestions and prepared it for publication as per the guide line. 


\section{References}

Alfaro, F. J., \& Jones, P. J. (2008). studies on the mechanism of aldehyde oxidase and xanthine oxidase. J. Org. Chem., 73, 9469-9472. https://doi.org/10.1021/jo801053u

Ayala, P. Y., \& Schlegel, H. B. (1997). A combined method for determining reaction paths, minima, and transition state geometries. J. Chem. Phys., 107, 375-384. https://doi.org/10.1063/1.474398

Bayse, A. C. (2009). Density-functional theory models of xanthine oxidoreductase activity: comparison of substrate tautomerization and protonation. Dalton Trans., 2306-2314. https://doi.org/10.1039/b821878a

Berry, E. C., \& Hare, M. J. (2004). Xanthine oxidoreductase and cardiovascular disease: molecular mechanism and pathophysiological implications. J. physio., 555, 589-606. https://doi.org/10.1113/jphysiol.2003.055913

Bjelaković, G., Stojanović, I., Bjelaković, G. B., Pavlović, D., Kocić, G., \& Milić, D., A. (2002). Competitive inhibitors of enzymes and their therapeutic application. Med. Bio., 9, 201-206.

Cao, H., Pauff, J., \& Hille, R. (2011). Substrate orientation and the origin of catalytic power in xanthine oxidase. Indian. J. chem., 50, 355-362.

Choi, Y. E., Stockert, A. L., Leimkuhler, S., \& Hille, R. (2004). Studies on the mechanism of action of xanthine oxidase. J. Inor. Biochem., 98, 841-848. https://doi.org/10.1016/j.jinorgbio.2003.11.010

Chowdhry, B. Z., Robert, R., Stephen, S., \& Dines, T. J. (2007). Computational chemistry using modern electronic structure methods. J. Chem.Edu., 84, 1364-1370. https://doi.org/10.1021/ed084p1364

Civcir, U. P. (2001). A theoretical study of tautomerism of 6-thiopurine in the gas and aqueous phases using AM1 and PM3. J. Mol. Stru., 535, 121-129. https://doi.org/10.1016/S0166-1280(00)00586-8

Contreras, J. G., Lorena, A., \& Gerli, L. A. (2008). Conformational preference in 4,6-dimethyl-1,3-thioxanej. Chil. Chem. Soc., 53, 1400-1403.

Dinesh, S., Shikha, G., Bhavana, G., Nidhi, S., \& Dileep, S. (2010). Biological activities of purine analogs. J. Pharm. Scient. Innovation., 1, 29-34.

Enroth, C., Bryan, T. B., Okamoto, K., Nishinoi, T., Nishino, T., \& Pai, F. E. (2000). Crystal structures of bovine milk xanthine dehydrogenase and xanthine oxidase: structure-based mechanism of conversion. Proc. Nat. Acad. Sci., 97, 10723-10728. https://doi.org/10.1073/pnas.97.20.10723

Foresman, J. B. (1993). Exploring chemistry with electronic structure methods. $2^{\text {nd }}$ edition. Gaussian, Inc. Pittsburgh, Pennsylvania. 5-20.

Gaussian 03 versions 6.0 (Gaussian, Inc., Pittsburgh, PA) manual in the help menu F1 option. Haftom G., (2011). Theoretical studies on reaction mechanism of xanthine oxidoreductase enzyme bound to hetrocyclic substrates xanthine, hypoxanthine and allopurinol. MSc. Thesis. Arba Minch University, Ethiopia.

Hille, R. (2006). Structure and function of xanthine oxidoreductase. Eur. J. Inorg. Chem. 10, 1913-1926. https://doi.org/10.1002/ejic.200600087

Hille, R., Kim, H. J., \& Hemann, C. (1993). Reductive half-reaction of xanthine oxidase: mechanistic role of the species giving rise to the "rapid type 1 molybdenum (v) electron paramagnetic resonance signal. Biochem., 32, 3973-3980. https://doi.org/10.1021/bi00066a018

Ilich, P., \& Hille, R. (1999). Mechanism of formamide hydroxylation catalyzed by a molybdenum dithiolene complex: a model for xanthine oxidase reactivity. J. Phys. Chem. B, 103, 5406-5412. https://doi.org/10.1021/jp9904825

Kalra, S., Jena, G., Tikoo, K., \& Mukhopadhyay, K. A. (2007). Preferential inhibition of xanthine oxidase by 2-amino-6-hydroxy-8-mercaptopurine and 2-amino-6-purinethiol. Bio.Medic. Chem., 8, 1471-2091.

Kim,Y., Jang, H., Y., Cho,H., \& Hwang, S. (2010). Tautomers and acid dissociation constants of 6-selenoguanine from density functional theoretical calculations. Bull. Korean Chem. Soc., 31, 3013-3016. https://doi.org/10.5012/bkcs.2010.31.10.3013

Leimkühler, S., Stockert, A. L., Igarashi, K., Nishino, T., \& Hille, R. (2004). The role of active site glutamate residues in catalysis of rhodobacter capsulatus xanthine dehydrogenase. J. Biol. Chem., 279, 40437-40444. https://doi.org/10.1074/jbc.M405778200

Martz, E. (2002). Protein explorer: easy yet powerful macromolecular visualization, Trends in Biochem. Sci., 27, 107-109. https://doi.org/10.1016/S0968-0004(01)02008-4

Mohamed, A., Al-Omar, M. A., El-Subbagh, H. I., Beedham, C., \& Smith, J. (2005). Role of molybdenum hydroxylases 
in diseases. Saudi Pharm. J., 13, 1 - 13.

Nishino, T., Okamoto, K., Eger, T. B., Pai, F. E., \& Nishino, T. (2008). Mammalian xanthine oxidoreductase mechanism of transition from xanthine dehydrogenase to xanthine oxidase. Fed. Euro. Bio. Sci. Journal., 275, 3278-3289. https://doi.org/10.1111/j.1742-4658.2008.06489.x

Okamoto, K., Matsumoto, K., Hille, R., Eger, B. T., Pai, E. F., \& Nishino, T. (2004). The crystal structure of xanthine oxidoreductase during catalysis: implications for reaction mechanism and enzyme inhibition. Proc. Nat. Acad. Sci., 101, 7931-7936. https://doi.org/10.1073/pnas.0400973101

Pauff, J. M., Cao, H., \& Hille, R. (2008). Substrate orientation and catalysis at the molybdenum site in xanthine oxidase: crystal structures in complex with xanthine and lumazine. J. Biol. Chem., 24, 1-17.

Pauff, J. M., Cao, H., \& Hille, R. (2009). Substrate orientation and catalysis at the molybdenum site in xanthine oxidase: crystal structures pictures in complex with xanthine and lumazine. J. Biol. Chem., 284, 8760-8767. https://doi.org/10.1074/jbc.M804517200

Pauff, J. M., Zhang, J., Bell, C. E., \& Hille, R. (2007). Substrate orientation in xanthine oxidase, crystal structure with 2-hydroxy-6-methylpurine. J. Biol. Chem., 282, 1-16.

Romao, J. M. (2009). Molybdenum and tungsten enzymes: a crystallographic and mechanistic overview. Dalton Trans., 21, 4053-4068. https://doi.org/10.1039/b821108f

Schramm, V. L. (1998). Enzymatic transition states and transition state analog design. Annu. Rev. Biochem., 67, 693-720. https://doi.org/10.1146/annurev.biochem.67.1.693

Schwarz, G., \& Mendel, R. R. (2006). Molybdenum cofactor biosynthesis and molybdenum enzymes. Annu. Rev. Plant Biol,. 57, 623-647. https://doi.org/10.1146/annurev.arplant.57.032905.105437

Senthilkumar, L., \& Kolandaivel, P. (2003). Post hartree-fock and density functional theory studies on tautomerism of 6-thioxanthine in gas phase and in solution. J. Mol. Stru., 638, 69-78. https://doi.org/10.1016/S0166-1280(03)00546-3

Voityuk, A. A., Albert, K., Romao, M. J., Huber, R., \& Roesch, N. (1998). Substrate oxidation in the active site of xanthine oxidase and related enzymes. a model density functional study. Inorg. Chem., 37, 176-180. https://doi.org/10.1021/ic9707570

Xia, M., Dempski, R., \& Hille, R. (1999). The reductive half-reaction of xanthine oxidase. Reaction with aldehyde substrates and identification of the catalytically labile oxygen J. Biol. Chem., 274, 3323-3330. https://doi.org/10.1074/jbc.274.6.3323

Zhang, X. H., \& Wu, Y. D. (2005). A theoretical study on the mechanism of the reductive half-Reaction of xanthine oxidase. Inorg. Chem., 44, 1466-147. https://doi.org/10.1021/ic0487301

\section{Copyrights}

Copyright for this article is retained by the author(s), with first publication rights granted to the journal.

This is an open-access article distributed under the terms and conditions of the Creative Commons Attribution license (http://creativecommons.org/licenses/by/4.0/). 